\title{
Design Situation and A New Design Idea of Potato Digging Shovel
}

\author{
Ping Zhao \\ Engineering College, Shenyang Agricultural University \\ Shenyang, China \\ E-mail: zhaopingxdg@163.com
}

Jizhe Zhao*

Engineering College, Shenyang Agricultural University Shenyang, China

E-mail:1219085444@qq.com

*Corresponding author

\author{
Lu Wang \\ Engineering College, Shenyang Agricultural University \\ Shenyang, China \\ E-mail:1422308305@qq.com \\ Xuewei Bai \\ Engineering College, Shenyang Agricultural University \\ Shenyang, China \\ E-mail: xw_bai@yahoo.com.cn
}

\begin{abstract}
To design a new digging shovel of tomato harvester with high performance, this paper summarizes the types of potato digging shovel at home and abroad, analyzes the structure and characteristics of various digging shovels, outlines some of the basic design methods and related theory, and discusses the existing problems of them. On this basis, this paper proposes a new bionic design plan and a new parameter design theory, and gives specific ideas so as to provide direction for following digging shovel design, which is of great significance in improving the design of the potato digging shovel and in optimizing the tuber crops harvest soil dynamics analysis method.
\end{abstract}

Keywords- Agricultural Machinery; Potato Digging Shovel; Design Situation; Bionic Design; Discrete Element

\section{INTRODUCTION}

The potato is the fourth major food crop after wheat, rice and maize in the world [1], and both its planting area and output in China have raised to the top of the world since 2006. Chinese Academy of Agricultural Sciences, the National Food and Nutrition Advisory Committee and China National Seed Association held the potato staple development strategy workshop on January 6, 2015 in Beijing. The meeting pointed out that researchers should promote potato staple in the future, expand planting area from the current 80 million hectares to 105 million hectares under the premise of without occupying three major staple foods, and make potato gradually become Chinese fourth major staple crop after rice, wheat and corn.

With the advance of Chinese potato staple food, its production scale has been expanded year by year, which will necessarily boost the development of the potato entire production mechanization. The harvest mechanization is the key to realizing the mechanization of potato production and an important factor that restricts the development of potato industry rapidly [2]. Potato harvest is laborintensive, accounting for $80 \%$ of the total labor intensity [3] and the mechanized harvest level is less than $20 \%$, far less than $70 \%$ of international standards [1]. Potato harvester can be roughly divided into three basic types, including digging plow, excavators and combine harvester. No matter what type it is, digging shovel is the direct working components with tuber roots and soil, so its design is very important and has been researched all the time, but there are some problems in the process of its development. First, the products introduced from abroad cannot coordinate with cultivated land condition and agronomic requirement, and are expensive; after-sales service and part supply are convenient. Second, digging shovel developed by China is plane or downward inclined arc (Fig. 1), which makes all tuber and soil be pushed to separating component, cannot plow the soil, lead to larger resistance and more energies. Finally, the designs lack accurately and reasonably basic theory, and were implemented according to experience and test.

This paper aims to point out the current existing problems, propose a new design idea and provide a reference and foundation for the following study through analyzing the structure type of the potato digging shovel and its design theory situation.

\section{TYPES AND CHARACTERIST ICS OF POT ATO DIGGING} SHOVEL IN CHINA AND ABROAD

\section{A. Types and characteristics of traditional digging shovels}

For a long time, researchers have made great efforts on studying the design of digging shovel, made very significant achievement, and some fixed shovel shapes were proposed. The types of traditional digging shovels are almost the same at home and abroad. They can be divided into fixed, rotary, vibrating and reciprocating according to movement form; single spade shovel, double and multi shovel by working width or the number of shovel sheet; flat shovel(triangular shovel, Submit shovel), concave spade, trough-type shovel and so on in accordance with shovel shape [4-7], as shown in Fig. 1. Fixed triangular plane digging shovel (Fig. 1 a) is a kind of very common potato digging shovel, and it is characterized by simple structure, easy manufacturing and no power transmission, but it will make the soil obstruct and increase the resistance. The character of submit flat shovel (Fig. $1 \mathrm{~b}$ ) is not often to produce omission and is suitable for the soil with smaller viscosity, but it is hard to go into the soil and it is easy to wrap grass. Besides, its breaking soil capacity 
is weak and it will make soil obstruct. Multi-piece shovel (Fig. $1 \mathrm{c}$ ) is an improved design on the bas is of triangular flat shovel, which is characterized by high efficiency, no prone to omissions, easy to the soil, but the large amount of unearthed soil will also make soil obstruct. Concave shovel (Fig. $1 \mathrm{~d}, \mathrm{e}, \mathrm{f}, \mathrm{g}, \mathrm{h}$ ) has a good performance of going into the soil and some breaking soil capacity, but it also make soil obstruct.

Overall, there are various problems about traditional digging shovel, including large traction resistance, obstructing soil severely, high energy consumption, and the main reason is that their structures make soil and the roots of potato tubers be almost completely sent to separating device, and soil leakage can not be achieved as soon as possible.

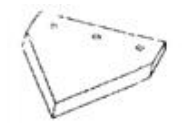

(a)

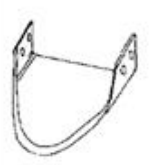

(e)

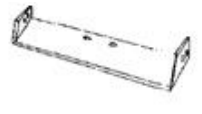

(b)

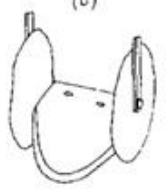

(i)

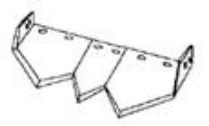

(c)

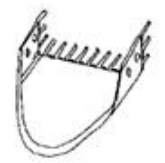

(q)

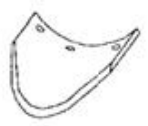

(d)

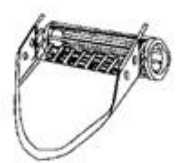

(h) (a) Triangular flat shovel (b) strip plane shovel (c) multi-piece shovel (d) concave shovel (e) a concave groove shovel (f) with rounded concave coulter blade $(\mathrm{g})$ with separate gates trough concave shovel (h) with imitation squirrel-cage plug with longitudinal groove concave shovel earth rolls

Figure 1. The forms of traditional digging shovel

\section{B. Structure and characteristics of new digging shovel}

Aiming at the problems of traditional digging shovel, researchers from Gansu Agricultural University in China began to do deeper research, a number of new digging shovels were designed according to the practice and process requirements. The following are some typical examples. Shi Linrong designed disc grating shovel[8], as shown in Fig. 2, which combined the grating shovel with the disc grating separation devices so as to improve the separation capability between the soil and potatoes; Dai Fei designed vibrating stepped digging shovel [9], as shown in Fig. 3, a ladder-like structure reduced the damage rate of potatoes and obstructing soil phenomenon, and it had good performance of breaking soil and separation, the load of separate components could be reduced by $20 \%$ $40 \%$, it significantly improved productivity and operations quality, but it needed vibration mechanism, had the complex structure, required power drive and had a large power consumption; Sun Bugong designed a grid type digging shovel [10], as shown in Fig. 4, the shovel with grating strip and the blade in the front reduced the contact area between the shovel and the soil, making digging resistance decrease; and Zhang Hua designed wing shovel[11], as shown in Fig. 5, its shape like wings made the resistance reduce in the digging process and it was not easy to damage the potatoes.

In addition, researchers from other countries also do some further study, and have developed some new digging shovels for potato. As shown in Fig. 6 and Fig. 7.

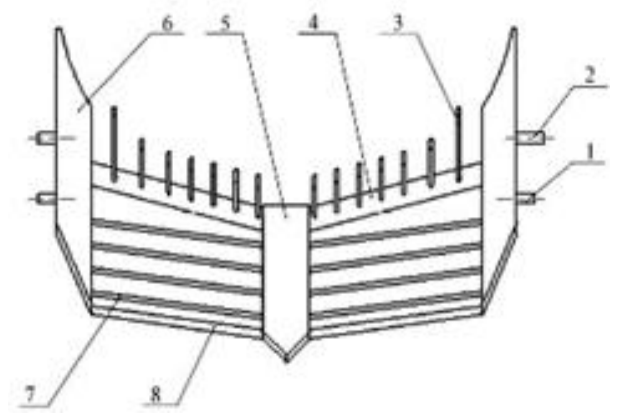

1-installing shaft 2-obliquity adjust axis 3- transportation potatoes board 4- reinforcement plate 5- The grave shovel 6Edge shovel 7-grid 8- Insertion board

Figure 2. Disc grating shovel

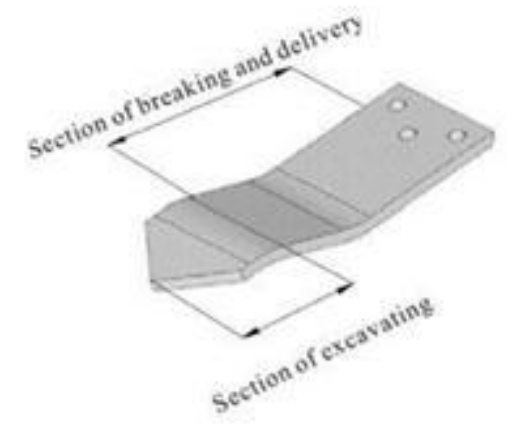

Figure 3. Stepped digging shovel

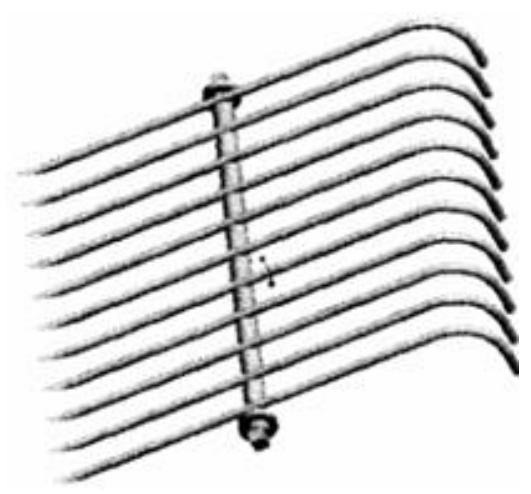

Figure 4. Grid type digging shovel

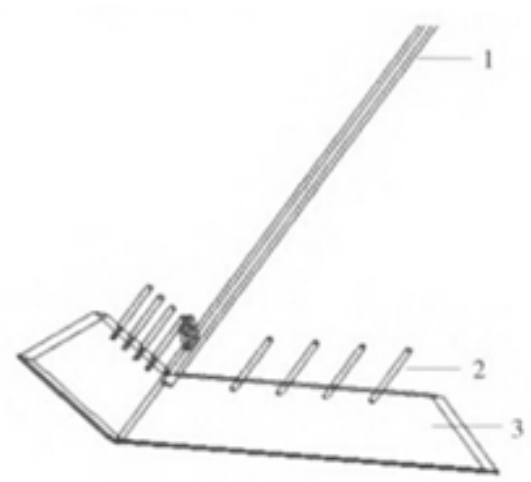

1-shovel handle 2-grid 3-wing shovel

Figure 5. Wing shovel 


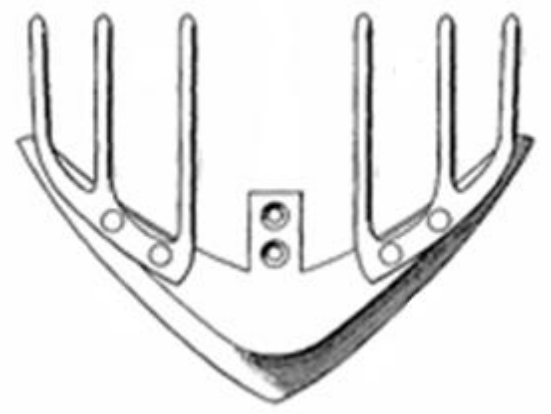

Figure 6. The two-wing shovel

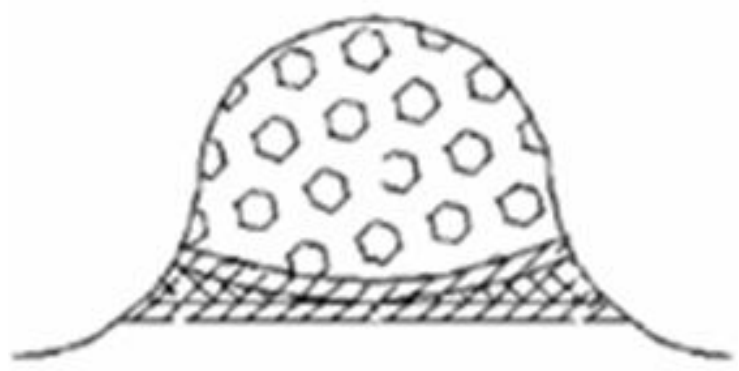

Figure 7. The arc-shaped shovel

III. DESIGN THEORY AND METHOD OF POTATO DIGGING SHOVEL IN CHINA AND ABROAD

\section{A. Current situations of design theory and method}

At present, Shape design of potato digging shovel is implemented through the experience and test, which is based on qualitative analysis of the performance mechanis $m$. The new digging shovels mentioned above are designed in this way.

Structural parameters design of potato digging shovel[12-17] is almost based on the theory that Cz.Kanafojski and T.Karwowski[18] presented, at the same time, combines static finite element analysis, stress analysis, continuum theory dynamics simulation and performance test to accomplish the design.

\section{B. Problems of design theory and method in China}

Affected by potato tubers and roots, the dispersion of soil surrounding tubers roots is relatively large, and the dispersion of the soil particles is larger in the digging process, and accompanied by dynamic rupture, collapse and flow, so the finite element method was used to simulate soil surrounding the potato tuber appears relatively reluctant.

In addition, regardless of the difference of form and mechanical properties between the potato tuber roots and the soil, the model is established through regarding them as soil, which is quite different with the actual situation.

\section{NEW DESIGN METHOD OF POTATO DIGGING SHOVEL}

\section{A. New design method of shovel shape}

The bionic design method based on wild boar arch mouth is proposed. Wild boar generally inhabits in forest, especially likes living in damp jungle near river, they regard fruit, vegetables and grassroots as food. When food is scarce, they go down the mountain to look for the crops of the farmers [19], such as potatoes, so the arch soil foraging behavior characteristic of wild boar is more prominent than pig. The "arch mouth" plays a key roll when they are foraging, and it is upper half of snout and extends on the eye, which front end is bare cartilage pad (rostrum), as shown in Fig. 8.

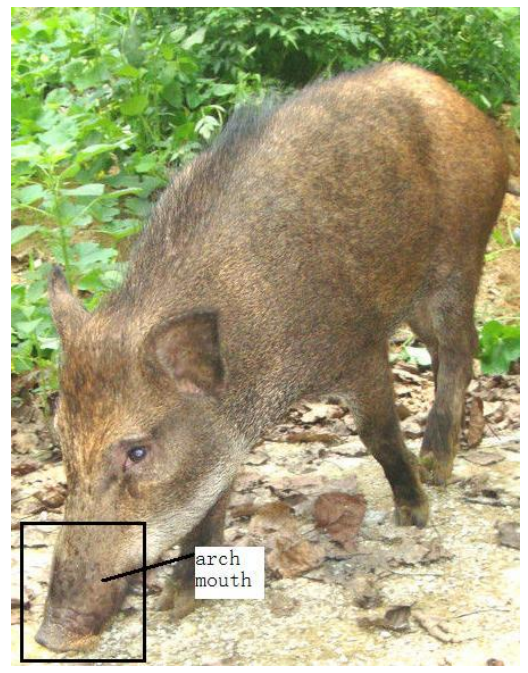

Figure 8 . Wild boar arch mouth shape

The basic idea is: based on reverse engineering technology, through the digital measurement, point cloud data processing and surface reconstruction, analyze surface features and information with arch mouth shape of wild boar, and design digging shovel surface with surface features like wild boararch mouth.

\section{B. New method of digging shovel structure parameter design and calculation}

Aimed at mechanics analysis problems of the current potato digging shovel structure parameter design and calculation, proposes the dynamics simulation method of shovel - soil - tuber - root system, which is based on fractal theory and combined with discrete element method and finite element method, use numerical workstations to simulate, analy ze potato tuber roots motion characteristics of surrounding soil after rupture - deformation - instability - separation - flow during the digging process and coupling effect with the digging shovel, clear the influence law that parameters of the digging shovel affect on the digging performance and achieve parameter optimization. Specific ideas are as follows:

- Set up 3D model of the potato tuber roots based on fractal theory and give mechanical characteristic parameters.

- Establish the effective model of soil particles group, test the physical and mechanical parameters of the soil around the root tubers at different distances, the outer layer of soil is represented by a finite element model, the inner soil is represented by a discrete element model, and establish the reasonable contact by using the method of combining the finite element and discrete element.

- On the basis of above, establish the digging shovel- soil-tuber-root display system dynamics simulation model and do the physical experimental 
verification and correction, do the simulation experiment on the basis of establishing reliable model, reveal the influence law that parameters of the digging shovel affect on the digging performance and achieve parameter optimization, and conclude the optimal structural parameters and working parameters.

\section{CONCLUSIONS}

(1) Design of potato digging shovel is related to the whole performance of potato harvester;

(2) Most of the current design methods are based on the qualitative analysis of the mechanism of performance, combined with the experience and test to carry out, the stress of the soil and the shovel body is limited to the finite element static analys is and dynamic analysis based on the theory of the continuum, and far from the actual situation. It is lack of the accurate and reasonable theoretical basis, can't get rid of the experience - half experience design, and most parameter optimization is single objective optimization aiming at mining least resistance, therefore, there is still room for improve the design and research of the potato digging shovel.

(3) Soil structure is relatively complex, the constant physical experiments and the repeating prototype developed are almost impossible, so how to establish the reasonable digging shovel - soil tuber - root system dynamics simulation model is a research direction of mining parts design in the future.

\section{ACKNOWLEDGMENT S}

This work was financially supported by Research Fund for the Doctoral Program of Higher Education of China (20132103120016) and the Science and Technology Planning Project of Shenyang City of Liaoning Province in China(F15-199-1-20).

\section{REFERENCES}

[1] Chen Hailiang, "Research Status and Existing Problems of the Potato Harvest Machinery," SCIENCE \& TECHNOLOGY INFORMATION, No. 20, July 2014, pp. 91, doi: 10.3969/j.issn.16723791.2014.20.068

[2] Wang Jianbo, Fan Qizhou, Tian Yanqing and Ma Min, "Research Status and Prospects of the Key Parts of Potato Digger," JOURNAL OF AGRICULTURAL MECHANIZATION RESEARCH, Vol.33, Jan. 2011, pp. 244-248 , doi: 10.13427/j.cnki.njyi.2011.01.030.

[3] Shi Mingming, Wei Hongan, Liu Xing, Hu Zhongqiang, Yang Xiaoping and Sun Guanghui, "The Present Situation of Potato Harvester Development at Home and Abroad," JOURNAL OF AGRICULTURAL MECHANIZATION RESEARCH, Vol.35, Oct. 2013, pp. 213-217, doi:10.3969/j.issn.1003-188X.2013.10.054
[4] Shmulevich I, Asaf $Z$ and Rubinstein D, "Interaction between soil and a wide cutting blade using the discrete element method," Soil and Tillage Research, Vol. 97, Nov. 2007, pp: 37-50, doi: 10.1016/j.still.2007.08.009.

[5] Li Baofa, Agriculture Mechanics, Bei Jing, China Agriculture Press, 2003.

[6] L.F.Johnson, "A Vibrating Blade for the Potato Harvester," Transactions of the ASAE, Vol. 17, May, 1974,pp: 867-873.

[7] Jia Jingxia, "Design and experimental research on the key part of potato harvester," doctoral dissertation, China Agricultural University, 2006, doi:10.7666/d.y939947.

[8] Shi Linrong, Wu Jianmin, Zhao Wuyun, Sun Wei, Wang Di, Li Hui and Liu Quan wei, "Design and experiment on potato digger of disc ce-grate type," Transactions of the Chinese Society of Agricultural Engineering, Vol. 28, Dec. 2012, pp. 15-21, doi: 10.3969/j.issn. 1002-6819.2012.24.003.

[9] DAI Fei, YANG Jie, ZHAO Wu-yun, FEI Qiang and TANG Xuepeng, "Experiment on working performance of potato digger with vibrat ing type of ladder shovel," Agricultuaal Research in the Arid Areas, Vol.32, May, 2014, pp. 263-267.

[10] SUN Bu-gong, LI Hui, WU Jian-min, SUN Wei and HUANG Xiao-peng, "Design and experimental study on the fense-like potato digging shovel," Journal of Gansu Agricultural University, Vol. 48, Jun. 2013, pp. 131-135, doi: 10.13432/j.cnki.jgsau.2013.03.015.

[11] ZHANG Hua,WU Jian-min and SUN Wei, "Experiment and finite element analysis on wing shovel type potato digger," Journal of Gansu Agricultural University, Vol.47, Aug. 2012, pp.127-129, doi:10.13432/j.cnki.jgsau.2012.04.013.

[12] Saka K S, Nanbu ST and Hata SI, etal. "Experimental Evaluation of Designing Parameters for a Vibrating Potato Digger," Journal of the Japanese Society for Agricultural Machinery, Vol. 53, May, 1991, pp. 93-98.

[13] Yonghua Zhang, Wangyun Ning and Yuqing Zhao, "Design and Virtual Test of Vibration-Type Digging Shovel," Lecture Notes in Electrical Engineering, Vol.216, Mar 2013, pp.216:855-864, doi: 10.1007/978-1-4471-4856-2_104.

[14] Tanas,w. "Optimal Depression Angle of Share in Sets of Digging Machine to Potatoes Harvest," Journal of Research and Applications in Agricultural Engineering, Vol.54, Jan. 2009, pp. 62-64.

[15] Abo-Elnor M, Hamilton R and Boyle J T, "Simulation of soil blade interaction for sandy soil using advanced 3D finite element analysis," Soil and Tillage Research, Vol.75, Jan. 2004, pp.61-73, doi: $10.1016 / \mathrm{S0} 167-1987(03) 00156-9$.

[16] A.A. Tagar , Ji Changying and Jan Adamowski, etal. "Finite element simulation of soil failure patterns under soil bin and field testing conditions," Soil and Tillage Research, Vol.145, Jan. 2015, pp.157-170, doi: 10.1016/j.still.2014.09.006.

[17] H. Bentaher, A. Ibrahmi and E. Hamza, etal. "Finite element simulation of moldboard-soil interaction," Soil and Tillage Research, Vol.134, Nov. 2013, pp.11-16, doi: 10.1016/j.still.2013.07.002.

[18] Cz.Kanafojski and T.Karwowski, Harvesting Machinery, China's Agricultural Mechanical Press, 1983.

[19] Zhang Dongjie, "The Boilogical Characteristics and Distribution Characteristics of Wild Boar," PIGS AND POULTRY, Vol.29, Mar. 2009, pp.80-81, doi: 10.3969/j.issn.1001-0769.2009.02.042. 